\title{
Research on Ability of Clean Energy Consumption of Electric Heating in Northern Areas
}

\author{
Luo Rui, Gao Ming, Guo Taiping, Chen Weiwei and Jing Shibo* \\ Economic and Technological Research Institute of State Grid Xinjiang Electric Power Co. Ltd, Xinjiang, China
}

\begin{abstract}
With the country's vigorous promotion of clean heating in the north, clean energy heating is becoming a trend. Using clean energy for heating can not only improve the grid's ability to consume clean energy, but also make an important contribution to reducing environmental pollution. Therefore, clean and pollution-free electric heating is currently the most important way of clean heating in northern areas. This paper takes an area in Xinjiang as an example, it not only analyzes the effect of regenerative electric heating on wind power absorption capacity, but also sorts out the current status of electric heating and related policies, which is of great significance to the promotion of electric heating in Xinjiang.
\end{abstract}

\section{Introduction}

Coal is one of the main fuel for heating in winter in the north. With the increasing depletion of fossil energy and the increasingly serious situation of energy saving and emission reduction, in order to reduce environmental pollution, electric energy replacement technologies such as electric heating have achieved significant development ${ }^{[1]}$. Reference [2-4] analyze the methods and characteristics of different types of electric heating, such as regenerative electric heaters and regenerative electric boilers, their economic and operating effects are also studied. Reference [5] compares central heating with decentralized heating. The analysis shows that decentralized heating is superior to central heating in terms of ease of use and heating fee collection, but central heating is safer, more energy-saving and environmentally friendly, and has a longer operating life than decentralized heating. Reference [6] points out that the choice of heating method should be combined with the geographical location of the heating area, climate characteristics and local policies and regulations. Reference [7] analyzes the changes of the grid load characteristics before and after the connection of the electric heating load. Reference [8] analyzes the planning method of the rural power grid after the electric heating load was connected. Reference [9-11] take Tianjin, Heilongjiang, Xinjiang and other places as examples to analyze the implementation of electric heating. Reference [12-13] study the comprehensive utilization of coal-to-electricity, wind power, photovoltaic and other new energy sources.

This article summarizes the electric heating implementation process from the aspects of electric heating type, implementation process, Xinjiang clean energy heating policy, etc., and analyzes the impact of regenerative electric heating on wind power absorption capacity from the actual situation of power grid operation.

\section{Analysis of current status of electric heating}

\subsection{Electric heating type}

According to different forms of heating, electric heating can be divided into centralized and decentralized. The specific classification of heating equipment is shown in figure 1:

*Corresponding author e-mail: 798291078@qq.com 


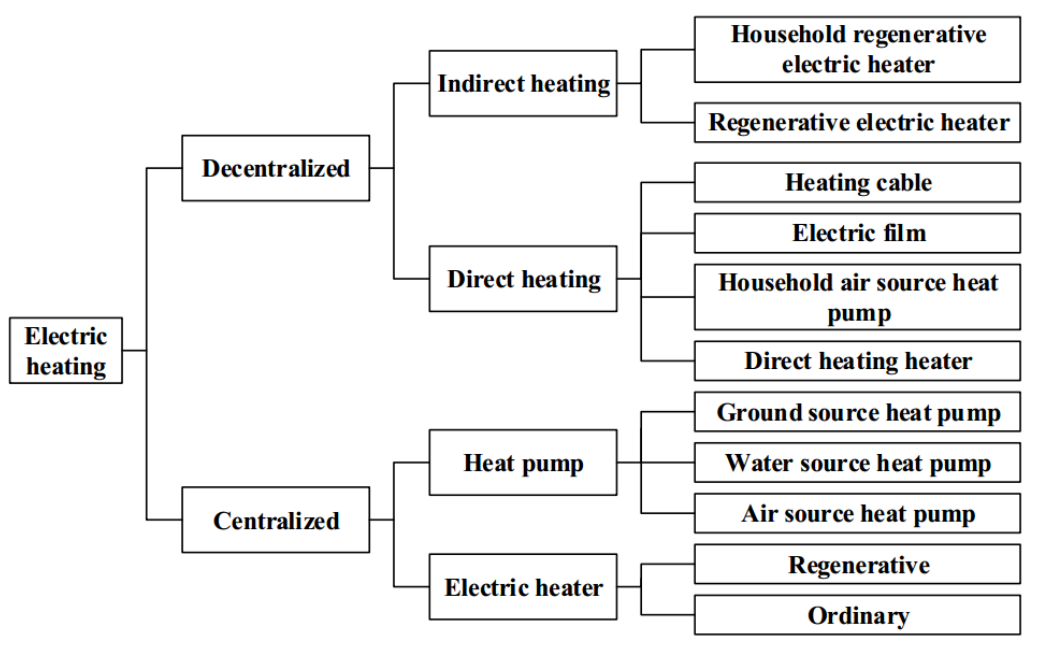

Figure1. Electric heating type diagram

Among them, regenerative electric heater is widely used. It uses low-cost electric energy in the trough period of the night grid to complete the conversion and storage of electricity and thermal energy within 6 to 8 hours. During peak hours of the power grid, the stored heat is released in the form of radiation and convection to achieve indoor heating 24 hours a day, which is economical and convenient. Therefore, this paper mainly focuses on the research of regenerative electric heating.

\subsection{Implementation process}

The implementation of electric heating will have a great impact on the power grid and users. Taking the application of regenerative electric heaters as an example, the implementation of electric heating requires the completion of supporting power grid construction and transformation, the purchase and installation of heating equipment, and energy-saving insulation and repair of houses. The specific implementation process of electric heating is shown in figure 2.

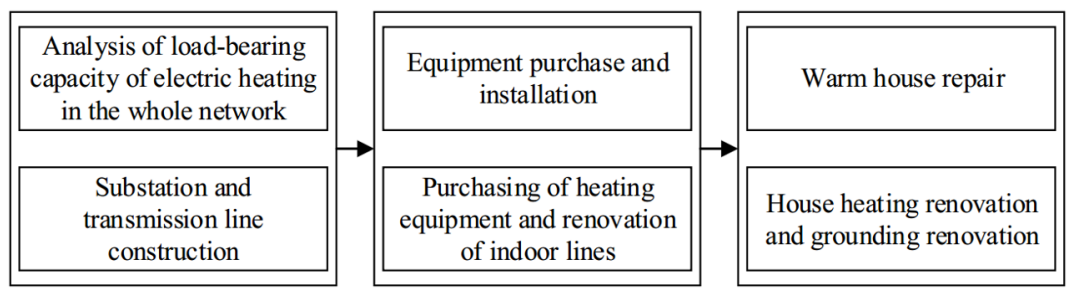

Figure2. Implementation flow chart

\subsection{Policy analysis}

In recent years, relevant government departments in Xinjiang jointly promulgated the pilot policy on direct transaction of transmission and distribution prices of electricity heating projects in Xinjiang and the guiding policy of heating price mechanism. The policy clearly defines the scope of the form of electric heating in Xinjiang and the components of preferential electricity prices, and clearly defines the boundaries between small-scale small-volume decentralized and large-scale large-volume centralized electric heating. It clarified the specific requirements of the dual-track preferential electricity price, and also made specific instructions for the different preferential electricity prices in the flat-peak and valley-peak electricity prices period and the flat-peak and valley-peak time period. The clear electric heating preferential policysignals can enhance the enthusiasm of users to participate in electric heating projects and accelerate the promotion of electric heating in Xinjiang.

\section{Analysis of wind power consumptive capacity of regenerative electric heating}

\subsection{Prospective analysis of cleaning energy heating in Xinjiang wind power generation}

Xinjiang is rich in wind energy resources and can be developed in large quantity. What's more, Xinjiang has nine wind regions with good wind energy quality. It has excellent wind energy resources for building large-scale wind farms ${ }^{[14-16]}$.However, the problem of wind curtailment in Xinjiang is also more serious. Power grid abandonment is very serious, which restricts the further development and utilization of wind power. At the same time, Xinjiang belongs to a temperate continental climate. Seasonal changes are very obvious. The winter is dry and cold. Its heating period is up to 6 months, and the heating energy demand is huge. Combining the characteristics of wind clean energy power generation and heating needs, the current status of the two can be effectively improved 
by using regenerative electric heating equipment for wind clean energy heating.

\subsection{Analysis of wind power consumptive capacity of power grid}

The randomness of the wind speed changes will make the wind power generation have the characteristics of uncertainty and peak inversion. This paper introduces the principle of probability mathematical statistics to count the output of wind farms in different regions at different times during winter heating. According to hourly statistics and longitudinal analysis, selecting the wind farm output at time $\mathrm{n}$ every day during the heating period, take $20 \%$ of the installed capacity of the wind farm as the interval, and taking the average value of the power value in the interval with the highest probability as the output of the time period. Then linearly superimpose the output of different wind farms at different times to obtain the spatial and temporal distribution characteristics of the wind power output curve in the region, and finally obtain the spatial and temporal distribution characteristics of the entire power grid wind power output curve in conjunction with the simultaneity of the grid's acceptance of the wind farm.

Based on the temporal and spatial distribution characteristics of wind power, the grid must have sufficient peak shaving capacity to ensure power balance and grid stability after large-scale wind power is connected. These characteristics should be comprehensively considered when studying the grid's ability to absorb wind power, and when multiple wind farms are connected to the grid, the simultaneous rate of wind farm output must also be considered ${ }^{[17]}$.

When the power grid is running normally, the peak shaving capacity of the system is:

$$
P_{r e s}=\sum_{n=1}^{N}\left(G_{n}-P_{n}\right)+P_{i}-P_{L}
$$

Where, $G n$ is the rated capacity of the generator set, $P n$ is the equivalent power load of the direct heating load of the power plant boiler, $P i$ is the interruptible load in the power grid, $P L$ is the power load of the entire network.

According to the parameters in literature [18], the grid's ability to absorb wind power can be expressed as:

$$
G_{w}=\frac{P_{r e s}}{\lambda \times \varphi}
$$

Where, $\lambda$ represents the simultaneous rate of multiple wind farms, $\varphi$ represents the reverse peak rate of wind power.

Combining the above two formulas can obtain the grid's ability to absorb wind power as:

$$
G_{w c}=\sum_{n=1}^{N}\left(G_{n}-P_{n}\right)+P_{i}-\frac{P_{L}}{\lambda \times \varphi}
$$

It can be seen from the above formula that the grid's ability to absorb wind power has a great correlation with the reverse peak rate and the simultaneous rate of wind power. However, because of the uncontrollable peak shaving rate of wind power, increasing the peak shaving capacity of the power system has become an important method to improve the grid's ability to absorb wind power.

\subsection{Analysis method of load-bearing capacity of regenerative electric heating in power grid}

When analyzing the carrying capacity of the electric heating load, it is necessary to comprehensively consider the requirements for stable operation of the power grid, the lines of various voltage levels, the load capacity of the main transformer, the change of the grid in the next year, the access of new equipment, etc. While ensuring the power supply capacity and the flexibility of the adjustment of the power grid mode, the capacity of the equipment to take the load is considered based on $70 \%$ of the transmission line rated power and $70 \%$ of the main transformer rated capacity. The specific analysis process is mainly divided into four steps. The first step is to make a statistical analysis of the average load rate and maximum load rate of each substation. Based on the analysis results, comprehensively consider the load capacity of $220 \mathrm{kV}$ equipment and $110 \mathrm{kV}$ equipment, remove the heavy-load main transformer and the main transformer connected to the heavy-load line, and determine the transformer with a certain capacity margin and the ability to connect with regenerative electric heating. The second step is to determine the typical daily load curve of the transformer based on the two principles that the trend of the typical daily load curve is consistent with the trend of most daily load curves and that the day with the largest load is selected as the typical day. The third step divides the typical daily load curve of the transformer into 24 intervals (one point per hour), andcalculates the margin capacity of a single transformer at different times according to the statistical results of the whole point load of the transformer. The calculation formula is:

$$
P_{R}=\tau S_{N} \times 70 \%-1.05 \max \left(P_{n^{\prime}} P_{n-1}\right)
$$

Where, $P_{R}$ is the marginal capacity of the transformer at time $n, \tau$ is the power factor, $S_{N}$ is the rated capacity of the transformer, $P n$ is the whole point load value at time n.

The final step is to superimpose the electric heating load capacity margins in each area in time-sharing, and obtain the electric heating load carrying capacity of the entire power grid in different time periods.

\subsection{Analysis of wind power dissipation capacity of regenerative electric heating}

Regenerative electric heating mainly introduces heat storage equipment in the electric heating system to increase the time constant of the heating system. After adopting regenerative electric heating, the impact on the system's peak shaving capacity is mainly manifested in 
three aspects. First, the pressure of the direct heating load of the boiler in the power plant is reduced, and the boiler capacity can be used for power generation. Secondly, the time constant of the heating system is usually several hours, and the introduction of heat storage increases the time constant of the heating system, which can achieve daily adjustment, so the load of thermal storage electric heating can be classified as an interruptible load. Finally, the increase of the grid load after regenerative electric heating is actually the regenerative electric heating load minus the load on the operation of a conventional heating boiler must be less than the load on regenerative electric heating. Therefore, the wind power absorption capacity of the power grid after using regenerative electric heating can be expressed as:

$$
G_{w c 1}=\frac{\sum_{n=1}^{N} G_{n}+P_{i}+\Delta P_{i}-\left(P_{L}+\Delta P_{L}\right)}{\lambda \times \varphi}
$$

Where, $\Delta \mathrm{P}_{i}$ represents the increment of the interruptible load in the power grid, and $\Delta \mathrm{P}_{L}$ represents the increment of the total load of the power grid.

Then the increase of the grid's consumption of wind power after the electric heating load is connected can be expressed as:

$$
G_{\Delta}=\sum_{n=1}^{N} P_{n}+\Delta P_{i}-\frac{\Delta P_{L}}{\lambda \times \varphi}
$$

Since the value of $\Delta \mathrm{P}_{L}$ is less than the load of regenerative electric heating, then the $G_{\Delta}$ value is positive, that is, the use of regenerative electric heating can effectively improve the ability to absorb clean energy wind power.

\section{Case analysis}

Take an area rich in wind resources in Xinjiang as an example. There are five administrative areas in the area. Each administrative area has a thermal power plant that undertakes heating tasks during winter heating. Wind power is mainly connected to the grid from the fifth area.The district heating index is $27.71 \mathrm{~W} / \mathrm{m}^{2}$, and the winter heating load can be calculated from the district heating index and heating area.The relevant parameters of each area are shown in table 1 .

Table 1. Power generation and heating load

\begin{tabular}{ccccc}
\hline $\begin{array}{c}\text { Administrative } \\
\text { regions }\end{array}$ & $\begin{array}{c}\text { Heating area } \\
/ \mathrm{m}^{2}\end{array}$ & $\begin{array}{c}\text { Heating load } \\
\text { /MW }\end{array}$ & $\begin{array}{c}\text { Electric heating carrying } \\
\text { capacity/MW }\end{array}$ & $\begin{array}{c}\text { Thermal power } \\
\text { capacity/MW }\end{array}$ \\
\hline NO.1 & 7350000 & 203.67 & 325.7 & $330 * 2$ \\
NO.2 & 8630000 & 239.14 & 299.4 & $200 * 4$ \\
NO.3 & 6460000 & 179.01 & 350.9 & $300 * 2$ \\
NO.4 & 6200000 & 171.8 & 301.6 & $330 * 2$ \\
NO.5 & 3220000 & 89.23 & 222.1 & $200 * 3$ \\
\hline
\end{tabular}

It can be seen from table 1 that the electric heating load carrying capacity of each administrative area is greater than the heating load.During winter heating, each thermal power plant is considered the smallest way. The equivalent power load of the direct heating load of the power plant is $15 \%$ of the rated capacity of the generator set. Then, power generation output of each power plant during winter heating is shown in table 2 .

Table 2. Power generation output of each power plant

\begin{tabular}{ccccc}
\hline $\begin{array}{c}\text { Administrative } \\
\text { regions }\end{array}$ & $\begin{array}{c}\text { Power plant direct } \\
\text { heating load/MW }\end{array}$ & $\begin{array}{c}\text { Power generation } \\
\text { /MW }\end{array}$ & $\begin{array}{c}\text { Heating boiler } \\
\text { load/MW }\end{array}$ & $\begin{array}{c}\text { Generating } \\
\text { margin/MW }\end{array}$ \\
\hline NO.1 & 99 & 480 & 28.800 & 81 \\
NO.2 & 120 & 595 & 20.825 & 85 \\
NO.3 & 90 & 423 & 17.766 & 87 \\
NO.4 & 99 & 474 & 14.220 & 87 \\
NO.5 & 90 & 435 & 17.400 & 75 \\
\hline
\end{tabular}

From the formula in the previous section and the data in table 2, it can be concluded that after using regenerative electric heating, the power generation capacity margin of the regional grid and the interruptible load in the grid have increased.

After analyzing the space-time characteristics of wind power in this area, the peak rate of wind power reverse regulation is 0.63 , and the wind power simultaneous rate is 0.77 . Table 3 shows the peaking capacity of the system and the ability to accept wind power after using regenerative electric heating.
Table 3. Comparison of wind power acceptance capacity before and after electric heating

\begin{tabular}{ccc}
\hline Electric & System peak shaving & Wind power \\
heating access & capacity/MW & acceptance/MW \\
Before & 415 & 855 \\
After & 913 & 1882 \\
\hline
\end{tabular}

It can be seen from figure 5 that after the use of regenerative electric heating, due to the increase in the capacity margin of the generator set and the interruptible load in the grid, the peak shaving capacity of the system is increased from $415 \mathrm{MW}$ to $913 \mathrm{MW}$, and the wind 
power acceptance capacity of the grid increased from 855.49 MW to 1882.09 MW. The use of regenerative electric heating can effectively improve the grid's ability to absorb wind power.

\section{Conclusion}

This paper analyzed the impact of regenerative electric heating on wind power dissipation capacity through specific cases based on the actual situation in Xinjiang. The results show that the use of regenerative electric heating has improved the ability of the grid to absorb wind power. This result is conducive to the adaptability requirements of clean energy access to the grid, balancing the fluctuation brought by wind power output to the grid, proving the feasibility and necessity of promoting clean energy power generation and heating in Xinjiang, and providing theoretical support for the promotion of electric heating projects using clean energy power generation.

\section{References}

1. Tong Zhiqiang. (2016) Research on Related Issues of Implementing Electricity Substitution in Hebei Southern Power Grid.D. North China Electric Power University.

2. He Xiqing, Wang Zhouxuan, Li Xiaojiang, et al. (2012) Electric heating water source heat pump and other heating systems' operation effectanalysis. J. Power demand side management, 14(3):28-32.

3. Zhang Jian, Wu Liang, Yuan Xinrun, et al. (2015) Application analysis of decentralized electric heating in Tianjin. J. Power demand side management, 17(6): 33-36.

4. Lin Kunping, Zhang Yinping, Di Hongfa, et al. (2004) Thermal performance of shaped phase change material heat storage floor electric heating system. J. Journal of Tsinghua University (Natural Science Edition),44(12):1618-1621.

5. Li Xingwen, Chen Degui. (2007) Magnetohydrodynamics of air switch arcSimulation and characteristic simulation. J. Chinese Society for Electrical Engineering, 27(21): 31-37.

6. Li Xingwen, Chen Degui. (2007) Research overview of mathematical model and characteristics of air switch arc. J. High voltage electrical appliances, 43(4): 269-273.

7. Liu Yanru, Yang Weihong, Wang Ji, et al. (2017) Load characteristic analysis of rural power grid before and after the "Coal to Electricity" Project. J. Electrical Technology,18(4):110-115.

8. Gao Ze, Chen Dengming, Yang Jianhua, et al. (2015) Grid planning research of rural low-voltage distribution considering"Coal to Electricity" Project. J. Electricians Electric (5):1-5.

9. Yuan Xinrun, Wu Liang, Zhang Jian, et al. (2015) Tianjin's electricity replacement situation and electricity heating experience economic analysis. J. Power demand side management, 17(5):24-29.

10. Meng Yi. (2010) Influence of Electric Heating on Construction and Operation of Heilongjiang Power Grid. J. Heilongjiang Power,32(2):149-150.

11. Xiong Jian, Li Yiyan, Liu Lihui, et al. (2013) Xinjiang Electric Heating Market Status. J. Xinjiang Electric Power Technology (2):69-70.

12. He Huimin, Wang Haiyan, Ren Jie, et al. (2016) Feasibility Study of Using Wind Power to Abandon Wind Power to Replace Electricity with Winter Heating. J. North China Electric Power Technology, (1): $1-5$.

13. Lv Quan, Jiang Hao, Chen Tianyou, et al. (2014) Based Thermal Power Plant Wind Turbine Consumption Plan and Its National Economic Evaluation. J. Automation of Electric Power Systems, 38(1): 6-12.

14. Wang Kai. (2016) Prospects for Xinjiang Wind, Solar and Storage Complementary Power Generation. J. Shanghai Electric Technology, 9(4): 26-28.

15. Ma Guidong, Ma Liya, Ma Xiaodong, et al. (2016) Feasibility analysis of large-scale heating of clean energy such as wind power in Changji, Xinjiang. J. Heating and cooling (9): 24, 26.

16. Gong Zhenqing, Li Dongdong. (2011) Study on heating mode of wind power in wind power enrichment area. J. China Electric Power Education (30): 97, 99.

17. Wu Gonggao, Ye Zhongxiong, Yaoming, et al. (2011) Analysis and Research on Anhui Power Grid's Ability to Accept Wind Power. J. East China Power, 39(6): 97-99.

18. MilligAN M. (2003) Wind Power Plants and System Operation in the Hourly Time Domain. In. AWEA Wind Power Conference, Austin Texas, May 18-21. 